\title{
Conditions for coaching to contribute to the adjustment of black African professionals
}

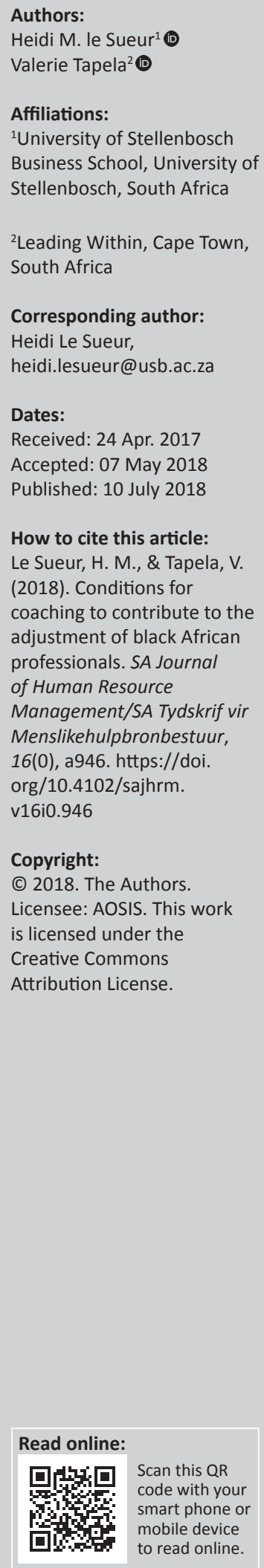

Orientation: Efforts to attract and retain black African professionals in Cape Town-based organisations are often met with challenges. Coaching has been identified as a potential strategic contributor for developing a sense of inclusivity and successful adjustment for black African professionals.

Research purpose: The study investigated the contribution that coaching makes and aimed at understanding the conditions required for coaching to support the adjustment process during relocation.

Motivation for the study: Too little is known in South Africa of how coaching can impact the adjustment during relocation. There is a need to identify key conditions that would enable a successful coaching process for migrating groups in the larger South African context.

Research design/approach and method: A qualitative inductive methodology approach was followed to guide the study, consisting of 11 in-depth interviews with three different professional groups to elicit various perspectives.

Main findings: It can be concluded that coaching contributes to black African professionals' adjustment to living and working in South Africa. The success of the coaching outcome and capability for adjustment depends on the individual, the coach and the environment in which they work. The supporting conditions that were commonly found from the three professional groups were support and space for the individual, while depth and match played a key role according to coaches and human resource (HR) professionals.

Practical/managerial implications: This article provides guidelines and recommendations for HR and senior managers in any organisation that experiences a complexity infused by racial and cultural diversity within its internal and external context. The study shows ways in which coaching as a tool can be useful in dealing with cross-cultural dynamics that prevail in South Africa and South Africa-based organisations especially during relocation adjustment.

Contribution/value-add: The body of knowledge contributes to understanding coaching in a diverse society reflected in cross-cultural organisations and the key conditions influencing the coaching intervention during an adjustment process.

\section{Introduction}

The low retention rate of black African professionals who relocate to Cape Town from other parts of South Africa is a cause for concern. In a speech at the Cape Town Press Club, then Accelerate Cape Town's chief executive officer (CEO), Guy Lundy (2009), indicated that business needs to talk publicly about the challenge of being unable to attract and retain black African professionals. As part of their mandate to ensure the sustainability and viability of economic growth, Accelerate Cape Town asks where the black professionals are in the city, recognising that a city that is not representative of the countrys' demographics will not be economically sustainable (Lundy, 2009). Yet, by 2016, the percentage of black African professionals in Cape Town has increased by a mere $4 \%$ over a 10 -year period (Department of Labour, 2014). The apartheid history of the labour force and its discriminatory effects continue to be a talking point in different circles, and it is felt today by Cape Town-based organisations who struggle to attract and retain black African talent. Research has shown that the perceptions exist that this city is seen as an unattractive destination for African people to work and reside in (Surtee \& Hall, 2010). According to Jongens (2006), this city is seen as stuck in the ways of the Old Work Order, where the environment lacks energy and racial discrimination is still apparent. As noted by O'Flaherty and Everson (2013, p. 76): 'Today, South Africa is a complex patchwork of racial, language and cultural groupings'. It is therefore important to explore ways to embrace the diversity opportunities in South Africa, especially to improve retention of black talent. 
There is a need to build inclusive and enabling environments in South Africa where people of all backgrounds feel a sense of belonging. Human resources (HRs) specialists in South African organisations who suffer the consequences of employees leaving because of the perceived barriers to the achievement of employment equity for black African people (Surtee \& Hall, 2010) will find this study relevant in their recruitment and retention strategies of black professionals from outside Cape Town. While this study utilised the unique characteristics experienced by Cape Town-based organisations, the supporting conditions for successful coaching around the adjustment process are relevant for any migrating groups in the larger geographical South African context.

\section{Purpose}

Coaching has been suggested in previous research and other instances as part of a strategy to help with the adjustment for black professionals wanting to live and work in Cape Town (Lundy, 2009; Surtee \& Hall, 2010). Very little is known about how and what coaching contributes to the adjustment process so that a direct link can be made. This article gives insights to the question on the conditions required for coaching to contribute successfully to the adjustment process. The insights can be applied by HRs personnel, senior management, coaches and black professionals themselves. It was not the aim of the study to explain the reasons why black African professionals seemed to find Cape Town 'unwelcoming' as was performed in the previous research (Surtee \& Hall, 2010). This article provides guidelines for coaching, not only relevant for Cape Town-based organisations but also for any organisation that experiences complexity infused by racial and cultural diversity.

\section{Literature review}

The authors acknowledge that South Africa has faced major shifts at an economic, political and social level in a short span of time. In April 1994, there was a change from an exclusive government to an inclusive dispensation. With this episodic change, organisations had to transform, and this was largely enforced through the introduction of laws such as Affirmative Action, then later Broad-based Black Economic Empowerment (B-BBEE) (Booysen, 2007). With all these came challenges and triumphs as society sought to fit into the new dispensation.

Studies conducted in the South African context, specifically by Myers (2013) and Surtee and Hall (2010), revealed that there are factors that inhibit the progression of black executives in their career and that barriers for achieving employment equity are found. These studies identified factors and barriers as being lack of experience and access to mentorship, the hostility of the environment, negative stereotyping, the sense of isolation and exclusion from a homogenic Eurocentric organisational culture. A common example of 'negative stereotyping' in which competencies and skills of black professionals are constantly tested, amounted to the unspoken pressure to see whether they have the capability to perform, which these professionals felt their white counterparts are not subjected to (Booysen, 2007; Myers, 2013; Surtee \& Hall, 2010). This common finding illustrates how the identified barriers mentioned are at play within organisations.

The next section explores theories on social identity, cultural intelligence, race theory and how these are relevant for management coaching as a strategic intervention for employee adjustment and retention.

\section{Social identity}

Social identity influences racial identity, particularly in post-apartheid South Africa, which, in turn, influences self-categorisation and self-concept. It is a 'cognitive theory which holds that individuals tend to classify themselves and others into social categories and that these classifications have a significant effect on human interactions' (Booysen, 2007, p. 3). Our social identity serves as a lens with which one categorises what one sees, who one is and what one makes interpretations about ( $\mathrm{O}^{\prime}$ Flaherty \& Everson, 2013). Employees' cultural differences should therefore not be overlooked. Laurie (2011) acknowledges that presently societal changes are still being dictated by or bound within racial categories. He asks how South Africans can un-think or un-learn old categories of citizenship and move beyond their own political bondage. While Booysen (2007) emphasised that it would be naïve to think that social identity issues in the South African organisational landscape would ever completely be done away with, the coaching process can provide the space to make people aware of the multiple identities that they operate under and reflect on how those might be influencing behaviours and choices (O'Flaherty \& Everson, 2013), for example, in the workplace. Especially the past trauma of apartheid, effects of exclusion and the ambivalent manner that black professionals seem to engage with their newly acquired privileges can be addressed in the containment of coaching (Motsoaledi \& Cilliers, 2012).

\section{Cultural intelligence during relocation}

Cultural Intelligence as a concept has potential in helping to understand cross-cultural dynamics and interactions in our modern world. As a construct, cultural intelligence has only been introduced to management literature recently and thus at present there is no generally accepted definition or operationalisation of it (Ang et al., 2007). Earley (2002) refers to cultural intelligence as a person's capacity to adapt to new cultural settings based on multiple facets including cognitive, motivational and behavioural features (Earley, 2002). In adjustment cases for professional expatriates, Earley and Mosakowski (2004) found it useful to measure the role that cultural intelligence had on experiences which people had. According to $\mathrm{Li}$ and Jackson (2015), there are three main categories of international expatriates' adjustment: the general adjustment to the local living conditions, the work adjustment 
to the overseas task and the interaction adjustment to host nationals. Organisations in South Africa are increasingly transforming into spaces where diverse groups of people interact. This exposure to different people and therefore cultures 'can have positive and negative effects on the psychological functioning and the well-being of employees within [the] organisation' (Laurie, 2011, p. 2). Among the black African professionals, Cape Town is perceived as unfriendly and seen as an 'un-African city' (Surtee \& Hall, 2010). For the adjustment process of black African professionals, similar to the adjustment of expatriates, cultural intelligence can be seen as a key skill from both the organisational environment as well as the professionals themselves. In other words, in recruiting and retaining black African professionals, the organisational environment needs to appreciate the cross-cultural subtleties and the professionals themselves need to be aware of their own role in understanding and dealing with the dynamics relating to the new environment. Suggestions that black African professionals be treated as expatriates have led to the curiosity around what would constitute an effective attraction and retention strategy of such individuals (Lundy, 2009). In their study, Li and Jackson (2015) found that the support the organisation gives the expatriate contributes positively when it addresses and helps expatriates to manage their anxiety and uncertainty that is inherent in new cultural experiences.

\section{Critical race theory}

Influencing this study are ideas that coaching combines psychology and politics in order to gain an 'understanding and sympathy for the coachee's cultural worldview above and beyond any presenting issue' (Gordon, 2015, p. 15), and 'thereby show up the extent to which human psychology is intimately linked to, and in some ways conditioned or limited by, sociopolitical and historical forces of its situation' (Hook, 2004 , p. 85). Although not applying psychology, coaching is understood to have similar roots. This study acknowledges the influence this thinking has had in shaping its enquiry and rationale for singling out black African professionals in Cape Town. Scholars such as Frantz Fanon and Steve Biko are used to advance some of the thinking.

In his earliest teaching, Fanon cautioned against 'psychology depoliticising the terms of human experiences' (Hook, 2004). Inferring coaching from psychology, this points to the necessity that coaches look into the individual's sociopolitical and economic narratives that have had an influence on how they view themselves, others and their connection with their identity. Biko felt that the black man's task is to self-emancipate, break out of the shackles of learnt inferiority in order to exercise agency and retain their dignity beyond the political and environmental circumstances (Biko, 1978).

\section{Management coaching as a strategic intervention}

The essence of management coaching is 'helping leaders getting unstuck from their dilemmas and assisting them in transferring their learning into results for their organisations'
(O'Neill, 2000, p. 5). The coaching process is defined as a method where question frameworks and models are used to help clients to work out solutions to specific issues (StoutRostron, 2009). This intervention is (COMENSA):

a professional, collaborative and outcomes-driven method of learning that seeks to develop an individual and raise selfawareness so that he/she might achieve specific goals and perform at a more effective level. (online)

Given these definitions, HR managers and coaches need to be aware of the perceived barriers, their possible origins and the influence of social identity, especially in diverse workplaces in South Africa, so that these issues can be dealt with explicitly during the coaching process.

In the recent past, there has been an inclination to view organisations as race-neutral spaces (Nkomo, 1992). In the recent context, still, issues of social identity, developing culturally intelligent teams, have not been seen as key in affirming the different people the organisation attracts. Majority groups who are the minority in organisations have simply been added on and expected to blend in into the environment. These minority groups experience dissonance because of the overwhelming role their race plays in Cape Town's societal and social environment against a work environment which by and large does not overtly acknowledge it, interestingly adds to the 'otherness' that they report feeling (Surtee \& Hall, 2010). The motivation to stay in the Cape and withstand the usual work pressures in an organisation is then impacted. It is recognised that employee retention is, however, not influenced by a single factor, but rather by multiple factors that affect retention in an organisation (Fitz-enz, 1990). The HR department as described by Acton and Golden (2003) plays an active role in retaining its employees, and therefore, HR professionals have been included in this study

\section{Method}

It was the purpose of the study to explore the contribution of coaching to the adjustment of black African professionals, aimed specifically at understanding the conditions and perspectives of the coaching experience of the participants. With this purpose in mind, this study from a paradigm point of view lent itself to an interpretivist outlook (Babbie \& Mouton, 2014).

\section{Research approach}

The study followed a qualitative inductive methodology approach with the primary goal of 'describing and understanding rather than explaining human behaviour' (Babbie \& Mouton, 2014, p. 270). Babbie and Mouton's (2014) description of a phenomenological approach further informed the manner in which the study was conducted. The rationale for undertaking a qualitative methodology was additionally based on the assertion that data gathering happens in the natural course of events and offers 'thick' descriptions of the event as it occurs. 


\section{Research design}

To achieve the aim and objectives of this research, the design was a case study. Case studies are understood as an in-depth study of how people experience a particular situation or phenomenon (Brink, 2006). The case study in this instance is the coaching experience.

This study was carried out using purposive sampling, based on the researchers' judgement and the purposes of the study (Babbie \& Mouton, 2014). During the process of setting up interviews, snowballing sampling was used as it proved difficult to locate and find suitable people to 'wander with in the research journey' (Henning, Van Rensburg, W. \& Smit 2004, p. 71).

Eleven individuals from the three groups of professionals were chosen to participate in this study (HR managers, coaches and coachees). The rationale behind the choices was justified using Laurie's arguments, which are that change programmes on cultural interventions often fail because they are implemented without the overall company strategy guiding it (Laurie, 2011). The study by Abbott, Stening, Atkins and Grant (2006), which explored coaching expatriate managers, guided the rationale for selection for this study as indicated in the overview of Table 1.

A semi-structured interview process was followed which involved unstructured and generally open-ended, probing questions and which intended to elicit views and opinions from the participants (Creswell, 2009). The interview guide was free-flowing, its structure being limited only by the focus of the research (Brink, 2006). The purpose of the interviews was exploratory and centred around the following question themes:

- the perceptions of how coaching contributed (or not) to the process of adjustment by each of the three professional groups

- the skills learnt (if at all) in aid of the adjustment

- the observations that were made, which provide evidence for the perceptions

- recommendations to members of their own professional groups and to the other two groups.

\section{Data analysis}

A thematic coding methodology was used to organise the material gathered from the interviews into chunks and segments of text before bringing meaning to the information (Creswell, 2009). During this process of data analysis, according to the traditional approach in social sciences, the researchers allowed the codes to emerge (Creswell, 2009).

\section{Ethical considerations}

The principles of protection of participants from harm, informed consent, the right to privacy, honesty and voluntary participation were adhered to in this study as outlined by Leedy and Ormrod (2001). The Research Ethics Committee of the Faculty of Economics and Management Studies, University of Stellenbosch, approved this research.

\section{Findings}

This study included three distinct different professional groups to shed insights from these three unique perspectives. The findings are therefore reported, firstly for each group, and then synthesised to illustrate the novel insights with practical implications for coaching interventions in Cape Town, and more generally for South Africa.

To understand the findings better, it is important to give an outline of some of the questions that were posed to the different groupings. For black professionals - the enquiry was about how well they think they have adjusted, the role they attributed to coaching that played a part in the adjustment process and finally any specific skills that they learnt in the process. For all groups, the final question was the recommendations that they would give to each other in aid of maximising the use of coaching. The coaches were asked to describe their client's experience of their coaching. They were asked to think about what in the coaching environment contributed, the skills the black professionals learnt that assisted in them adjusting to living and working in Cape Town. They had to further substantiate their responses through observations and feedback received from the HR managers. The HR managers were tasked with explaining their organisations' standpoint on the value of coaching as a strategic contributor, what evidence they saw

TABLE 1: Rationale, inclusion criteria and demography for participants.

\begin{tabular}{|c|c|c|c|}
\hline Professional group & Rationale & Criteria for inclusion & Demography \\
\hline HR managers & $\begin{array}{l}\text { HR managers are often buyers of coaching } \\
\text { services and custodians of the relocation } \\
\text { processes. They play an active role in the } \\
\text { retention of employees. }\end{array}$ & $\begin{array}{l}\text { - Relocation of black African professionals in their role } \\
\text { as HR managers in Cape-based organisations } \\
\text { - Provision of a coaching and/or mentoring programme } \\
\text { in their organisation to the black professionals who } \\
\text { were relocated. }\end{array}$ & $\begin{array}{l}\text { Count: Two white HRM and one black HRM } \\
\text { Industries: Retail and financial Services } \\
\text { Age range: } 25-40 \\
\text { Titles: Senior Human Resource Manager and } \\
\text { Regional Business Partner }\end{array}$ \\
\hline Coaches & $\begin{array}{l}\text { The coaching fraternity can benefit from a } \\
\text { better understanding of the extent of their } \\
\text { work, specifically during the adjustment } \\
\text { process after relocation to Cape Town. }\end{array}$ & $\begin{array}{l}\text { - Coaching assignment with black African professionals } \\
\text { who relocated in the past } 12 \text { months. } \\
\text { - Affiliation with a professional body such as COMENSA } \\
\text { (Coaching and Mentoring South Africa), ICF } \\
\text { (International Coaching Federation). }\end{array}$ & $\begin{array}{l}\text { Count: Two black coaches and three white } \\
\text { coaches } \\
\text { Age range: } 40-60 \\
\text { Level of education: Masters and PhD }\end{array}$ \\
\hline $\begin{array}{l}\text { Black African } \\
\text { professionals } \\
\text { coachees }\end{array}$ & $\begin{array}{l}\text { Captures perception of black professionals } \\
\text { as recipients of a coaching intervention in } \\
\text { order to understand their experience. }\end{array}$ & $\begin{array}{l}\text { Relocation to Cape Town took place in the past } 12 \\
\text { months } \\
\text { - Minimum of two or more years in a managerial or } \\
\text { executive position } \\
\text { - Had been assigned a coach in that period and had } \\
\text { undergone a minimum of four coaching sessions. }\end{array}$ & $\begin{array}{l}\text { Count: Three black women } \\
\text { Age range: } 25-35 \\
\text { Industry: Financial Services } \\
\text { Titles: Senior Managers in various roles } \\
\text { Cities relocated from: Johannesburg and } \\
\text { London }\end{array}$ \\
\hline
\end{tabular}

HR, human resources; HRM, human resource manager. 
and the skills learnt which supported the black professionals in their new roles and as new residents to Cape Town.

\section{Black African professionals' perception of coaching contribution}

The inference from the study is that coaching as part of a professional's development programme contributed to the coachees' adjustment to the life event of 'relocating', changing jobs and living in a new environment. The black African professionals in this study expressed four effective conditions: space, support, match and depth in their reflections, which are illustrated in the findings below. Notably, these are the benefits of having the space to reflect, getting support through the transition, enjoying an independent mirror reflecting their thoughts and gaining alignment professionally and personally. The following quote illustrates this condition:

'It (the coaching) provided a safe space so to speak.' (Participant B2, coachee)

'[...] it's definitely doing what I expected it to do which is to hold up a mirror to my blind spots'. (Participant B3, Coachee)

The findings from the interviews with black professionals were found to support the views of Hill (2010), Barday (2015) and Motsoaledi and Cilliers (2012), who found emotional support, thinking space, challenge and reflection as key aspects that contribute to the effectiveness of executives in a coaching process.

Factors that further assisted in the adjustment process were the level of initiative that coachees took in the coaching process, their openness with their coach, their willingness to be vulnerable and to receive feedback - both positive and negative. This was expressed in comments such as:

'I think it was probably me taking initiative' ... (Participant B1, Coachee)

'... I needed to hear the negative as much as the positives. It's not something people receive well but just for me to grow'. (Participant B1, Coachee)

In the study, it seems that black professionals, because of the significant changes in their lives, approached the coaching with some level of ownership. They engaged and wanted to be coached. The importance of executive engagement for coaching effectiveness has been confirmed previously (Hill, 2010). Executive engagement relates to whether the executive is taking initiative in the coaching, their attitude towards feedback, especially if it is negative, and their ability to open up and allow emotions to surface in the coaching so as to grow and gain new skills to navigate themselves in their new roles.

Other aspects that emerged related to the coach themselves, particularly in their objectivity, mutual respect, creating a safe space, depth of coaching as well as the race of the coach. The openness and ease to talk about race, issues relating to racism in the workplace and racial incidents while living and working in Cape Town were bigger when the coaches themselves were black. This was described as follows:
'It's not easy to raise a racial issue with a coach who's white, it's a lot harder [...] having someone black, you can relate on a different level. It made the conversation a lot more honest and I was also open to her criticism on those issues'. (Participant B1, Coachee)

Cornish (2009) and Pennington (2009) reveal in their findings that support and understanding on racial matters in cases might inform affinity towards race. To be open and avoid the twopersona dichotomy (Cornish, 2009), it can be concluded that the black African professionals would benefit from being clear about the focus and specific help they need, and on that basis find a coach who will best serve those needs. This informs the importance of match which repeatedly emerged in this study.

The participants identified that listening, embracing failure and being open to new things were learnt during coaching, and this helped them specifically with the adjustment to their new situation. As one coachee said:

'One thing I got out of my coaching sessions after a while was that I wasn't allowing myself the experiences in Cape Town and at work. I was too inward, so I realised the value of being open to trying out things'. (Participant B3, Coachee)

Socially and as a leadership competency, listening and the ability to see growth in failure are seen as key by Myers (2013) and Barday (2015). This further speaks to how coaching as an intervention is beneficial for the individual's personal development but becomes a benefit for the organisational effectiveness, for example, retention of skills as well.

\section{Coaches' perception of coaching contribution}

According to coaches, the biggest benefit for the coachees was greater awareness of themselves, insight into how they show up in their new roles, their new environment and their response to others. The following quote illustrates this aspect precisely:

'It's not about being a Joburg good black, it's facilitating how they themselves show up'. It's really about raising awareness, about their contribution to the work, it's about their perceptions of themselves'. (Participant C1, Coach)

Increased self-awareness as a personal competency is a key coaching outcome. O'Flaherty and Everson (2013), in their contribution to work regarding coaching in South Africa, stretch the idea of awareness by adding that it is for both the coach and the coachee to let the process of coaching unfold with awareness and commitment to challenging own assumptions, especially when coaching across social identity boundaries.

Given the loss of confidence that can result when an individual is in a new role, unsure of the new surroundings, different living conditions and lacking familiarity, the building of confidence is important as a coaching outcome. In her study, Bennett (2015) identified that a positive sense of identity helped to build confidence. In providing a safe space, a thinking space and ease, the coaching can increase the capacity to take on new challenges (Bennett, 2015). 
The explicit and deep engagement with the client issues in this safe space could be identified as a core factor to the conditions mentioned. One coach states this clearly:

'with their anxiety. Could be for example not having a sense of belonging, not having family, out of group. And that brings in lots of anxiety. The way to deal with it is to name it in the coaching' (Participant C3, Coach)

Bennett (2015) highlights the benefit of explicitly engaging with uncertainty and anxiety. To do that, coaches need to listen deeply to their client's language.

In a similar vein to the coachees, the match between coach and client, the skill to understand the client, the ability to challenge and to serve as a form of deep reflection for the client were identified as helpful conditions during the adjustment. These findings support Hill (2010), who highlights that the coach must challenge the executive to reflect deeply, think differently and see complex situations in new ways. It emerged in this study that understanding the client is twofold. It is essential that the coach understands both the client and additionally understands the unique South African environment in which the client works, to support them navigate with appropriate skills and techniques. This is illustrated by the following quote from one of the coaches:

'If you do not understand their situation, it will not work ... so if you don't get their culture and you don't get the culture they work in, then it will be difficult for you as a coach to understand and help them'. (Participant C2, Coach)

Coaches indicated the following skills and competencies as the ones that contributed to coaching helping with adjustment: cultural intelligence and emotional intelligence. From a coach's perspective, it was stated as follows:

'They (black African professionals) need cultural intelligence and they need personal and emotional intelligence very quickly to get into the English fabric of the company they're working in'. (Participant C2, Coach)

The findings underpin that cultural and emotional intelligence are about deep awareness: awareness of self, awareness of other, awareness of own culture, awareness of other's culture and awareness of how coachees relate to all of these. Earley and Mosakowski (2004) and Tompson et al. (2008) highlighted the indicators of cultural intelligence and what characteristics they have. As a new concept in management, cultural intelligence is still emerging and thus not many coaches explicitly use or know the principles thereof. Aligned to cultural intelligence is what Cornish (2009) introduces whereby the coachees need support in developing their own unique leadership style that reflects their cultural strengths but also incorporating what works from other cultures too. Therefore, if there is an explicit engagement and openness to talk about the perceived and/ or real discrimination, it can be unpacked to identify strategies that meet the needs of the coachee, as was confirmed in this study.
The coaches found the reflection on how their coaching helped during adjustment of black African professionals who moved to live and work in Cape Town helpful. The awakening that took place is an indicator of the need for coaches to be aware of the explicit issues that particularly black African professionals bring to the coaching session. Coaches acknowledged the coachees' difficulties with adjusting to the Cape Town life, on the one hand, and the need for them to be effective in their professional roles during times of change, transition and uncertainty, on the other hand.

\section{Human resource professionals' perception of coaching contribution}

The main benefit of coaching, according to HR managers, is that the employees (black African professionals) gained clarity, had the space to think about not only their new roles but also their contribution to the organisation, they received much-needed support given the pressures of their leadership roles and they became more conscious leaders. An observation from an HR manager illustrates these points:

'I watched these guys (coachees) become more conscious about how they are showing up to things. More conscious and selfaware, much more conscious of the impact that they have [...] as an executive, as a leader'. (Participant A1, HR Manager)

It has been emphasised by Day (2009) that executives need support in order for them to be effective in their roles through transition periods. This point was confirmed by an HR manager as well:

'It just gives space to not walk blindly through that life change. When you walk with intent through that transition and when you walk through that transition supported, it's a fundamentally different experience. I cannot even imagine expecting execs I work with to do these big life changes - moving to new cities, new jobs, new reporting roles, new functions beneath them, whatever it may be, without this type of support'. (Participant A1, HR Manager)

In the eyes of the HR managers, the conditions that contributed to the effectiveness of the coaching were mostly the match between coach and client, setting clear objectives for the coaching process, a safe space and the support the individual received from their work environment. The HR specialists recognise their responsibility to ensure that there is a match between coach and client and the support they can offer as an organisation.

\section{Discussion}

The analysis of the data revealed how coaching contributed to the adjustment of black African professionals. It can be concluded that coaching did contribute positively. This can, however, not simply be assumed to be the case; therefore, the findings specify the conditions that contribute to the successful outcome of the coaching intervention during a relocation adjustment process.

The research objectives guided how themes were clustered and how the findings are presented. Findings were interpreted 
including past literature or theories that either confirmed or diverged from it (Creswell, 2009). The authors identified the conditions that are of importance across all three professional communities, and then explored specific sub-conditions that matter to either one or two of the groups. This process was in accordance with West and Milan (2001), who discussed the conditions under which learning happens in a coaching process.

This study revealed that in most of the cases, adjustment was not an explicit goal in the coaching. In the course of being coached the issue of 'fitting in', adjusting to both working and social conditions emerged. This presents an opportunity for Cape-based organisations to support employees by seeking coaching in a deliberate manner, with adjustment as one of the explicit goals. This provides the coachees' difficulties of adjusting to work and social environment of Cape Town started with insights into how their social identities could be shaping their experiences and creating a barrier for them. As they experienced the 'exclusion', it became more insightful and useful for them to distinguish whether this was real or perceived exclusion. Cornish (2009) states this as an important distinction because performance and self-esteem are negatively impacted when one feels constantly discriminated and excluded.

It seems that the retention of black African professionals can be facilitated through the process of coaching where social adjustment is on the agenda. This is critical as it is one of the determining factors in the settling in of the individual. It gets the individual to reflect upon their self-categorisation lens and those they place on others, determining those lenses that are of use and those that are not. This means that coaching helps facilitate their sense of awareness and ability to empower themselves.

Equally, the organisational environment ought to be prepared and positioned for cultural inclusion and the competence and interest to retain (Livermore, 2015). Without the ability to adapt cross-culturally, there is a disconnection and therefore retention is compromised.

There is an immense weight upon the individual organisations in recognising that coaching can be seen as a positive contributor to retaining and settling in of black professionals. What is also evident, although not the main point of this study, is the sentiment that Cape Town as a city does not inspire the adjustment and settling in of the said professionals (Surtee \& Hall, 2010). Generally, issues cited have much to do with the cultural fit of the city. Its perceived unfriendliness, expensive lifestyle and the 'Eurocentricity' drives black African professionals away as previously conducted research shows. This points to the importance of coaches and organisations putting social adjustment on the agenda. Doing this helps the individual to ensure that their personal and professional goals align. Moving to Cape Town is then a life choice and not solely seen a career move.

\section{Practical implications}

The conclusion is that coaching contributes to black African professionals' adjustment to living and working in Cape Town. The success of the coaching experience and capability for adjustment does, however, depend on the individual, the coach and the environment in which they work. The supporting conditions that were commonly found from the three professional groups were: support, depth, space and match. Below is the synthesis of these core conditions paired with additional sub-conditions that stood out for each of the participating groups.

One main finding is the support for the individual. Both the environment and the coach have to be supportive and be open about what the black professional is experiencing. This means vulnerability, clarity on what is needed and recognition that coaching might not be the only contributor to the success in adjustment. Networking within and outside of the organisation is key in breaking down the social identity categorisation that often unconsciously emerges in society and in the work environment (Cornish, 2009). For the HRs community in Cape-based organisations, the essential discovery has been that coaching can be used as a strategic contributor to the attraction and retention of black African professionals. Providing support before they move, putting social adjustment on the agenda and being supportive of the executive's coaching journey is seen as a pivotal support function.

The authors recommend that a relocation within South Africa should indeed be managed similar to the relocation of an expatriate, given the complexity of the racial and social identities which was expressed by the participants of this study and which prevailed in South Africa and in Cape Town particularly. Coaching should, however, not be seen as the only contributor but part of a collective of support given to the person. The relocating organisation can assist proactively by supporting the individual via integration in professional networks - for example, industry-related and private groups of interest, therefore exposing them to different people and environments. Literature has highlighted that coaching can have great benefits for both the coachee and the organisation because in their contentedness and general well-being, people tend to perform better as they are well supported and feel acknowledged (Cornish, 2009).

In terms of coaches, their coaching contributes directly when there is depth in the interaction - when coachees are encouraged to reflect on their contribution to the situation, allowing them to understand their cultural capital and therefore learning from activities undertaken at work and in their personal lives. This invariably might mean breaking stereotypes that they themselves might have about themselves, their racial grouping, their gender, and so on. Openness to look at things differently, allowing new experiences, learning the new culture and embracing different living conditions forms part of successful adjusting. Part of transitioning is understanding that coachees have to 
relinquish the old, to consciously use the coaching journey to look at what is good and what works about one's culture and incorporating it with what one perceives to be good and successful about other cultures, essentially developing cultural intelligence. All of this must take place while ensuring that they remain true to themselves. Coaching contributes to the journey when there is consciousness of own leadership styles, willingness to integrate, understanding of other views and openness to complexity and multirealities.

Another relevant finding in this study is that for the coaching to be effective, the coach ought to acknowledge and allow a space for black professionals to express issues relating to their blackness. This often is about the pressures they feel in the workplace and what they feel they have to deliver because they are black. Sometimes, these might be real and at times these might be perceived. The key is to help them discern the difference and support them into making decisions about the appropriate actions where they leverage the strengths their background provides which allows the development of resilience. For the coaching to support and directly contribute to adjustment, the coach needs to understand and be aware of crosscultural diversity and social identity theories. Furthermore, the value of the process of contracting and getting clarity about what the focus is should not be underestimated. This antecedent allows for a key finding in this study making the issues explicit in this safe space: naming, acknowledging and tackling issues for what they are which allows measurement and therefore effectiveness of the coaching.

The fourth condition identified across all groups is the match between the coachee and the coach. In the context of South Africa, the coach must not only understand the adjustment challenges in the changing living, working and relationship conditions, but also further the unique dynamics in the South African work environment, given the complexities mentioned earlier. Further, the match is an enabler of other conditions, such as the depth of the coaching process as well. All three groups should assess the match so that the client finds a coach that best serves her or his needs. Figure 1 provides an overview on the conditions for coaching towards adjustment of black African professionals.

\section{Practical implications}

The practical implications that can be exercised by all three professional groups can be stated as follows:

- Plan the coaching process strategically to facilitate the relocation and adjustment process. Avoid it being a reactive and ad-hoc intervention.

- Include the development of cultural sensitivity and intelligence as a coaching objective as a means for effective adjustment to different living conditions and diverse cultures.

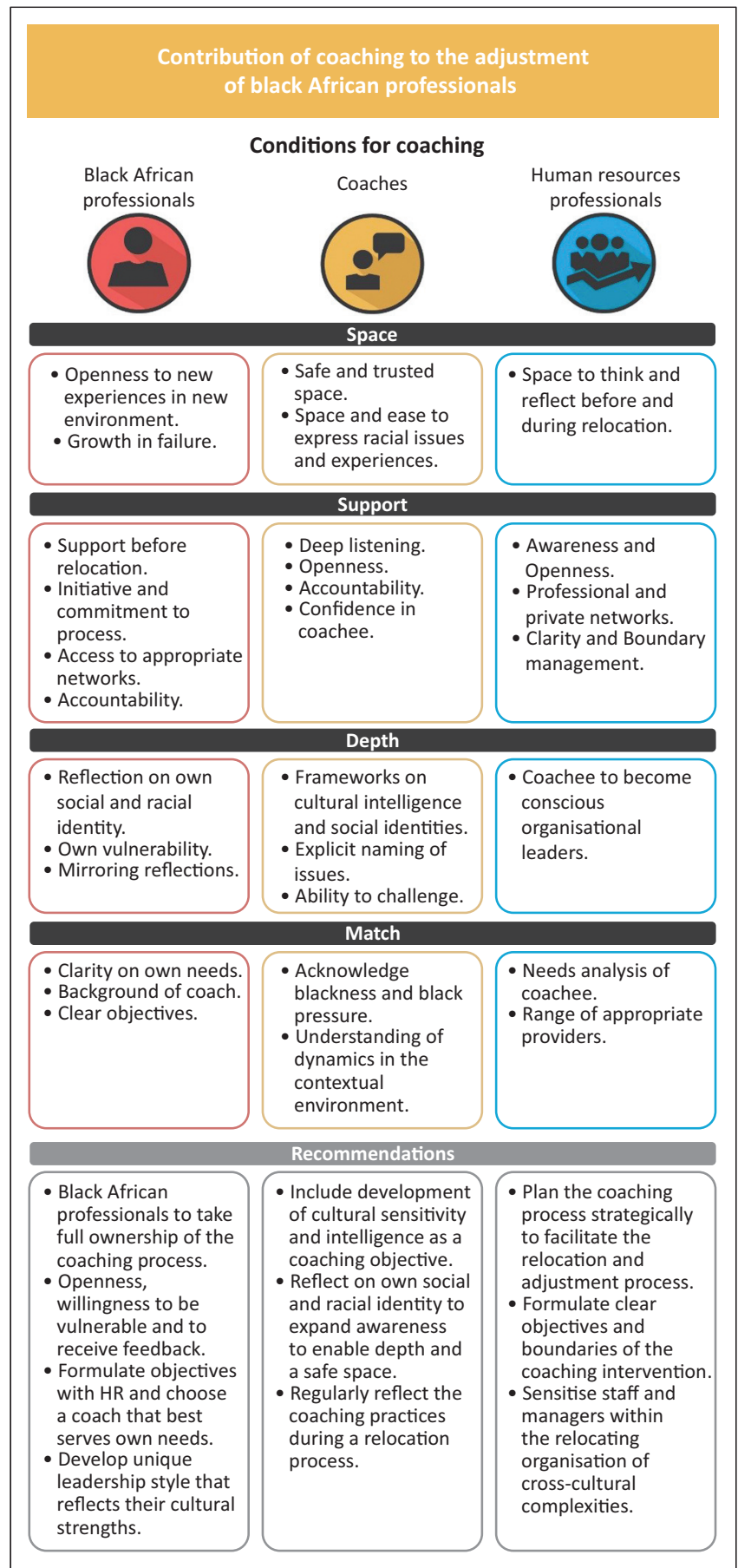

FIGURE 1: Coaching for the adjustment of black African professionals.

- Coaches need to reflect on their own social and racial identity to expand their own awareness to enable depth and a safe space for exploring coachees identities in the coaching process.

- Sensitise staff and managers within the relocating organisation of the cross-cultural complexities and diversity factors based on social identity theories, to enable such issues to be specified openly and courageously.

- Black African professionals need to take full ownership of the coaching process and request support before the relocation.

- Black African professionals need to plan to develop their own unique leadership style that reflects their cultural 
strengths and cultural capital and also be familiar with the complexity of diversity.

\section{Limitations and recommendations}

The research is confined to a limited number of black professionals who currently work and live in Cape Town after relocating to the Cape and having received coaching. Those who have left Cape Town and those who did not receive coaching during their relocation do not form part of this study.

As set out in the definitions, 'black' in this study refers to black Africans only. No Indian or mixed-race professionals were interviewed. White professionals as coachees were also excluded from this study. This is because of indications that the most significant problem of adjustment and feelings of exclusion lies primarily among black professionals (Surtee \& Hall, 2010). This is seen through the low retention rates of these professionals in Capebased organisations.

Black professional graduates were also excluded as their adjustment may have a different set of needs which would add complexity to the study. In their first year of work, graduates generally deal with 'complex issues surrounding identity and transition and the journey is multi-faceted and varied' (Dunne, 2013, p. 142).

In its focus, this study excluded black professionals from Cape Town. Those who were born, raised and now work in Cape Town in these same organisations that reportedly are unable to retain their relocated counterparts. Much can be learnt in further research about how they view and experience the corporate and social environments and whether this impacts on them continuing to work and live in Cape Town.

Given the limitation of the study, potential follow-up research could revisit those and other Cape-based organisations that have recently embarked on adjustment and supportive programmes for their newly recruited and relocated black African professionals to investigate what the coaching programmes achieved and how it contributed in the longer term. Additionally, those that did relocate to Cape Town and did not receive coaching can be included in further research to determine how their experience differs and to test the identified supporting conditions. This research could lead to tested frameworks and/or techniques that can further guide adjustment cases.

Cultural intelligence is a relatively new management concept with great potential for helping to understand effective skills in cross-cultural and multi-cultural organisations. Further research to investigate and gain a better understanding of cultural intelligence and its relation to the successful application in South African organisations would therefore be valuable to the field of management studies.

\section{Conclusion}

In the context of black African professionals during relocation, the findings from this study on contributions and the required conditions of coaching can be used to inform those in HR or other managerial roles and the coaching fraternity.

Coaches have an evidence-based right to claim that coaching can contribute to the adjustment of black African professionals to working and living in this case study, in Cape Town. The findings are useful in understanding the challenges that black African professionals encounter and ways in which coaching can be useful. It emerged that race does matter in organisations because of South Africa's particular history. The experience of real and/or perceived racism and discrimination in the workplace needs to be acknowledged in the coaching space. The greatest benefit in being explicit about these experiences is that the coach can challenge the thinking and beliefs of coachees, to help them leverage the positives of their own culture and to incorporate useful aspects from other cultures while remaining true to who they are.

As HR professionals have been included in this enquiry, Cape-based organisations can benefit from hearing the importance of supporting newly recruited black African professionals. The HR managers have indicated how coaching can be an answer to an effective retention strategy of individuals who need to adjust in work life, private life and in developing healthy associations.

In closing, this body of knowledge contributes to understanding coaching in a diverse society reflected in cross-cultural organisations and the key conditions influencing the success of the coaching intervention during an adjustment process.

\section{Acknowledgements}

V.T. was a master's student at Stellenbosch University, USB, and conducted the research as part of her dissertation for the fulfilment of the degree, Master in Philosophie in Management Coaching.

\section{Competing interests}

The authors declare that they have no financial or personal relationships that may have inappropriately influenced them in writing this article.

\section{Authors' contributions}

H.M.L.S. was the supervisor for V.T. during the research project and converted the dissertation into the journal article.

\section{References}

Abbott, G. N., Stening, B. W., Atkins, P. W. B., \& Grant, A. M. (2006). Coaching expatriate managers for success: Adding value beyond training and mentoring. Asia Pacific Journal of Human Resources, 44(3), 295-317.

Acton, T., \& Golden, W. (2003). Training the knowledge worker: A descriptive study of training practices in Irish software companies. Journal of European Industrial Training, 27(4), 137-146. 
Ang, S., Van Dyne, L., Koh, C., Yee Ng, K., Templer, K. J., Tay, C., \& Anand Chandrasekar, N. (2007). Cultural intelligence, its measurement and effects on cultural judgment and decision making, cultural adaptation and task performance. Management and decision making, cultural adaptation

Babbie, E., \& Mouton, J. (2014). The practice of social research. Cape Town: Oxford University Press Southern Africa.

Barday, M. A. (2015). Contribution of coaching, as part of the blended leadership programme towards a leader's development and leadership development. Research assignment presented in partial fulfillment of the requirements for th degree Master of Philosophy in Management Coaching. Stellenbosch: University of Stellenbosch.

Bennett, K. (2015). Making sense of and developing executive leaders' capability for uncertainty. Thesis submitted in fulfilment of the requirements for the degree of Philosophy Doctor in Personal and Professional Leadership. Johannesburg: University of Johannesburg.

Biko, S. (1978). Black consciousness and the quest for a true humanity. Ufahamu: $A$ Journal of African Studies, 8(3), 10-20.

Booysen, L. (2007). Societal power shifts and changing social identities in South Africa: workplace implications. South African Journal of Economic and Management Sciences, 10(1), 1-20.

Brink, H. (2006). Fundamentals of research methodology for healthcare professionals (2nd edn.). Cape Town: Juta.

COMENSA: Coaches and mentors of South Africa [website]. Coaching. Retrieved May 10, 2018, from https://www.comensa.org.za/Information/Coaching

Cornish, T. (2009). Coaching Black British coachees. In J. Passmore (Ed.), Diversity in coaching: Working with gender, culture, race and age (pp. 165-180). London: Kogan Page.

Creswell, J. W. (2009). Research design: Qualitative, quantitative and mixed methods approaches. 3rd edn. Thousand Oaks, CA: Sage.

Day, A. (2009). Effective executive transitions: Managing the entry process into a new leadership role. The Ashridge Journal, 1-5.

Department of Labour. (2014). 14th Commission for employment equity 2013-2014, annual report. Pretoria: Chief Directorate of Communication.

Dunne, I. (2013). Graduate identity development in the first year of work. Published Doctoral Dissertation. Johannesburg: University of Johannesburg.

Earley, P. C. (2002). Redefining interactions across cultures and organisations: Moving forward with cultural intelligence. Research in Organisational Behaviour, 24, 271299.

Earley, P. C., \& Mosakowski, E. (2004, October). Cultural intelligence: Best practice. Harvard Business Review, pp. 1-9.

Fitz-enz, J. (1990). Getting and keeping good employees. In Personnel, 67(8), 25-29.

Gordon, L. R. (2015). What Fanon said: A philosophical introduction to his life and thought. New York: Fordham University Press.

Henning, E., Van Rensburg, W. \& Smit, B. (2004). Finding your way in qualitative research. Pretoria: Van Schaik.
Hill, G. (2010). Executive coaching: Perspectives of effectiveness from executive coaches. Masters Research report. Queensland: Queensland University of Technology.

Hook, D. (2004). Frantz Fanon, Steve Biko, 'psychopolitics' and critical psychology. London: LSE Research Online. Retrieved May 10, 2016 from http://eprints.Ise. ac.uk/961

Jongens, C. (2006). To what extent do the different social environments in Cape Town and Johannesburg influence the organizational culture of the company in those places and how does this impact on the ways that Black African managers navigate borders and negotiate identity in the workplace. Unpublished Masters research report. Cape Town: University of Cape Town.

Laurie, R. A. (2011). Positive acculturation conditions and work related outcomes: The Mediating role of integration. Unpublished Master's thesis. Potchefstroom: North-West University.

Leedy, P. D., \& Ormrod, J. E. (2001). Practical research: Planning and design (7th edn.) Upper Saddle River, NJ: Pearson Education, Inc., Publishing as Merrill

Li, N., \& Jackson, M. H. (2015). Global relocation: An examination of the corporate influence on expatriate adjustment. Asia Pacific Journal of Human Resources, 53, 471-489.

Livermore, D. (2015). Leading with cultural intelligence: The real secret to success (2nd edn.). New York: American Management Association.

Lundy, G. (2009, January 22). Where are Cape Town's black professionals? Speech presented at the Cape Town Press Club, Cape Town.

Motsoaledi, L., \& Cilliers, F. (2012). Executive coaching in diversity from the systems psychodynamic perspective. SA Journal of Industrial Psychology, 38(2), 1-11.

Myers, H. (2013). Factors in South Africa inhibiting the progression of black executives in their careers and the role of coaching in their development. Master of Management research report. Johannesburg: University of Witwatersrand.

Nkomo, S. (1992). The emperor has no clothes: Rewriting 'race in organizations'. Academy of Management Review, 17(3), 487-513.

O'Flaherty, C., \& Everson, J. (2013). Coaching in South Africa. In J. Passmore (Ed.) Diversity in coaching: Working with gender, culture, race and age (pp. 75-86). London : Kogan Page.

O'Neill, M. B. (2000). Executive coaching with backbone and heart: A systems approach to engaging leaders with their challenges. San Francisco, CA: Wiley.

Pennington, G. (2009). Coaching black American coachees. In J. Passmore (Ed.), Diversity in coaching: Working with gender, culture, race and age (pp. 181-194). London: Kogan Page.

Stout-Rostron, S. (2009). Business coaching wisdom and practice. Randburg: Knowres.

Surtee, S., \& Hall, M. J. (2010). Transformation: African people in the Western Cape: An overview. Development Policy Research Unit. (DPRU working paper No.10/141).

Tompson, H. B., Bear, D. J., Dennis, D. J., Vickers, M., London, J., \& Morrison, C. L. (2008). Coaching: A global study of successful practices. Current trends and future possibilities 2008-2018. New York: American Management Association.

West, L., \& Milan, M. (2001). The reflecting glass: Professional coaching for leadership development. London: Palgrave. 